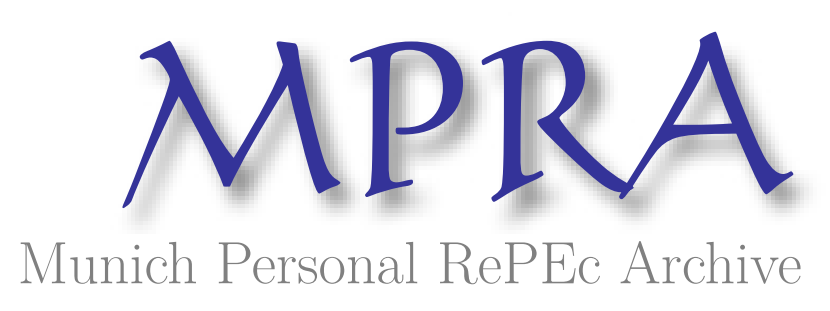

\title{
Relative Deprivation in China
}

Chen, Xi

Yale University

8 January 2013

Online at https://mpra.ub.uni-muenchen.de/48582/

MPRA Paper No. 48582, posted 24 Jul 2013 23:37 UTC 


\title{
Relative Deprivation in China
}

\author{
Xi Chen*
}

Yale University

(First Draft Prepared for The Oxford Companion to the Economics of China)

January 8, 2013

Relative deprivation (RD), also known as relative poverty ${ }^{1}$, an idea implicitly put forward by Adam Smith in The Wealth of Nations in $1776^{2}$ and formally conceptualized by Runciman (1966), refers to the discontent people feel when they compare their positions to others and realize that others in the group possess something that they do not have. The issue of RD is important to the Chinese people as reflected in the traditional saying "it is better to be the head of a chicken than the tail of a phoenix", which suggests that taking a relatively good position benefits people in the Chinese society. More importantly, $\mathrm{RD}$ is also a pressing issue in China. China has experienced unprecedented uneven growth during the last three decades of economic reform, which has been accompanied by worsening inequality. This entry briefly reviews the key

*Yale University, xi.chen@yale.edu. Copyright 2013 by Xi Chen. All rights reserved. Readers may make verbatim copies of this document for non-commercial purposes by any means, provided this copyright notice appears on all such copies.

${ }^{1}$ In contrast to absolute deprivation (or absolute poverty) that applies to all underprivileged people, relative deprivation comes from a comparison to the reference group. While economic growth may be accompanied by massive absolute poverty reduction, relative deprivation may not change as long as inequality persists.

${ }^{2}$ Adam Smith (1776, Book 5, Chapter 2, Article 4) documents the role of a linen shirt in eighteenth century Europe:

"A linen shirt, for example, is, strictly speaking, not a necessary of life. The Greeks and Romans lived, I suppose, very comfortably though they had no linen. But in the present times, through the greater part of Europe, a creditable day-labourer would be ashamed to appear in public without a linen shirt, the want of which would be supposed to denote that disgraceful degree of poverty which, it is presumed, nobody can well fall into without extreme bad conduct." 
measures of RD and major empirical findings using them. I also discuss some of the most pressing policy issues with regard to RD.

RD has been defined along various socioeconomic distributions, such as general consumption (Easterlin, 2001), status goods consumption (Cooper et al., 2001), income (Yitzhaki, 1979), perceived economic welfare (Ravallion and Lokshin, 2010) and subjective financial status (Wildman, 2003b). Easterlin (2001) captures RD by own consumption relative to a weighted average of others consumption, and Cooper et al. (2001) measures RD as quantity and quality of status good consumed relative to peer group members. However, the measure of RD based on income, such as in Yitzhaki (1979) and Wildman (2003a), is more widely used in empirical studies.

Some China studies make attempts to capture RD at the community level using the widely accepted Gini coefficient. Li and Zhu (2006) measures RD by community-level Gini coefficient and finds its significant association with selfreported health status, and the relationship appears as an inverted-U shape. That is to say, rising Gini coefficient tends to improve health when Gini index is low, and to harm health when Gini index is above a certain level. Meanwhile, Gini coefficient increases the likelihood and frequency of health-compromising behavior such as smoking and alcohol consumption. To the contrary, Gini coefficient in Ling (2009) does not explain any of the health outcomes and health behavior investigated except probability of high waist circumference.

Intuitively, the aggregated community Gini coefficient may mask heterogeneous micro level incentives and therefore imprecisely implement the idea of RD. Theoretically, Yitzhaki (1979) shows that the aggregation of relative deprivation in a community is a function of Gini coefficient. Therefore, aggregate income inequality goes further than RD to implicitly hypothesize that even the least relatively deprived people may still suffer the adverse impacts of high inequality. In other words, the strong hypothesis suggests that inequality directly influence outcomes through channels independent of RD.

To weaken the strong inequality hypothesis to test heterogeneous RD impacts, Jin et al. (2010) interacts Gini coefficient with different income groups, attempting to capture various $\mathrm{RD}$ motives along the distribution. Their results indicate that income inequality has a negative (positive) impact on households' consumption (savings) in China. Consistent with the status seeking motive, 
people, especially the poorer and younger groups, save and increase education investment to improve their social status when social status is tied to pecuniary and non-pecuniary benefits. Rising income inequality strengthens this incentive by increasing the benefit of improving status and enlarging the wealth level required for status upgrading.

Other community level RD measures, such as skewness and kurtosis statistic, are used in China studies. Skewness measures the relative asymmetry of income, and kurtosis measures the peakedness of the distribution, both of the two statistics and their interaction are good measures of local density in tails of income distribution. Brown et al. (2011) documents systematic relations between social spending and changes in higher order terms of the income distribution, i.e. skewness, kurtosis and their interaction, in rural China. Specifically, they find that the relatively deprived increase spending on funerals and gifts as competition for status intensifies. Moreover, lower ranked families of grooms (but not brides) increase spending more on wedding ceremonies as local income competition increases.

Studies using the mean (or median) income of a community as a proxy for relative income generate mixed results (Marmot et al., 1991; Gerdtham and Johannesson, 2004). For relevant China study, Carlsson and Qin (2010) uses this measure and conducts a survey-based experiment to elicit people's preferences regarding relative standing. They find that poor Chinese farmers care about relative status to a high degree comparable to previous studies in developed countries. Mangyo and Park (2011) applies the measure and verifies the negative impact of RD status on self-reported health and psychosocial health.

More precise measures of $\mathrm{RD}$ gauge the individual level deprivation specifically via the differences between this individual's income and the incomes of the richer members of the group. One would feel more deprived as the number of individuals in society with higher income increases. An overall measure of $\mathrm{RD}$ for an individual, also known as relative deprivation of absolute income (RDA), is given by summing the differences in income and weighing it with the number of people in a reference group. One concern with RDA is that it does not take into account differences in the scale of the income distribution across reference groups. In other words, if everyone's income doubles, rela- 
tive deprivation will double as well. This would be a problem, for example, when tracking RD over time using panel datasets. Even if people view withinreference group income differences in proportional terms, RDA still overstates relative deprivation of individuals in high-income reference groups. To improve upon it, relative deprivation over individual income (RDI) is defined as the ratio of RDA relative to the individual's own income. Using both RDA and RDI measures, Li and Zhu (2006) find insignificant impact of RD on self-reported health status in China.

Intuitively following the measure of Gini coefficient as the ratio of the area between Lorenz curve and the line for uniform distribution to the area below uniform distribution line, Wildman (2003b) proposes another measure of individual-specific RD incorporating the cumulative proportion of total income and population up to the individual. Using this measure, Ling (2009) finds that among older adults in China Gini coefficient and the RD measure have different and significant effects on health outcomes and behavior, but those less relatively deprived are not necessarily healthier than those more relatively deprived.

Observing the different patterns of migration for the richest group and the poorest group, Stark and Yitzhaki (1988) develops a RD model that complements the utility-social welfare approach. In another independent literature, Deaton (2001) proposes a measure of relative deprivation widely used in the literature that integrates the model of mortality and income with the animal and human evidence on inequality and health. The two measures, Stark and Yitzhaki (1988) measure and Deaton (2001) measure, are very close to each other. The Deaton RD measure takes normalized differences between the average income of those with higher income and this individual's income weighted by the proportion of those with income higher than the individual. Compared with the Stark and Yitzhaki (1988) measure, the Deaton RD measure is further divided by average community income to normalize the RD index.

Four immediately advantages of the Deaton RD index follow. First, large scientific evidence, such as in the field of public health, psychology, animal science, and economics and so on, lays solid foundation for the index. Second, it takes into account the scale issue that tends to overestimate RD in highincome groups when incomes differ substantially across groups or in evaluating 
RD status over time using panel datasets. Third, relative to some other RD indexes, such as RDI, the Deaton RD is more sensitive to income distribution. Fourth, the Deaton RD is bounded between 0 and 1, which facilitate the magnitude of empirical findings.

Using the Deaton RD measure, Ling (2009) concludes those with higher levels of RD have lower odds of high waist circumference ${ }^{3}$, increase nutritional intake $^{4}$, reduce their probability of being overweight ${ }^{5}$, and raise their probability of ever smoking ${ }^{6}$. However, their probability of being underweight, hypertension and current smoking behavior are not significantly affected. To account for the recent escalating household social spending in China, Chen et al. (2012) studies gift books kept by households in rural western China and documents that the relatively deprived households spent much higher budgets on gifts and festivals. On average, these scarce resources are barely enough to cover wasteful status games, such as hosting costly weddings, funerals and other ceremonies. As a consequence, children born to mothers in more relatively deprived households are more likely to suffer from malnutrition indicated by low height-for-age z-score and stunting status (Chen and Zhang, 2012) ${ }^{7}$.

All relative status measures above presume that the distance between two agents matters, either in proportional or absolute terms. However, studies on animals suggest rank over distance in importance. Unlike most of the other measures, rank is unaffected by changes in the shape of the income distribution. Rank ignores the magnitude of income differences among individuals. A higher level rank means a lower level RD. Li and Zhu (2006) and Sun and Wang (2012) utilize individual's rank over incomes within the reference group. $\mathrm{Li}$ and $\mathrm{Zhu}$ (2006) finds that the harmful effect of income inequality on health

\footnotetext{
${ }^{3} \mathrm{An}$ increase in RD lowers the probability of having high waist circumference by 65.9 percentage points for the national sample.

${ }^{4} \mathrm{An}$ increase in $\mathrm{RD}$ results in an increase of 0.1 day's worth of nutritional intake for the national sample.

${ }^{5} \mathrm{An}$ increase in $\mathrm{RD}$ reduces the probability of being overweight for an average individual in the full sample by 53.4 percentage points.

${ }^{6}$ Increases in RD raise the odds of ever smoking cigarettes by 132.9 percentage points among the full sample.

${ }^{7}$ Doubling the number of prenatal exposures to social ceremonies in a village would lower the height-for-age z-score of children born to poorest 50 percent families by 0.54 standard deviation and raise their stunting rate by 0.48 standard deviation. Moreover, the more relatively deprived the household, the higher marginal detrimental effect there is to its child health outcomes.
} 
does not vary with income rank, though lower individual rank corresponds to worsened health outcomes. Sun and Wang (2012) examines that a household's consumption rate is negatively related to its income rank within a community. The negative impact on total consumption is mainly reflected in the expenditures on housing, education, clothing and eating out.

The definition of reference group is vital to all RD measures. Reference groups can be defined quite differently in specific contexts. In a developed society, information flow is fast and efficient, such that reference groups are not straightforward. However, in an impoverished traditional community, poor public infrastructure drags resource flow, and the evolution of local norms strengthens reciprocity. These differences facilitate a much improved definition of reference group. Substantial ethnographic evidence documents social interactions more appropriate at the village level, than in city blocks, census tracks, schools or classrooms, in less-developed rural communities. Mangyo and Park (2011) suggest that village reference groups are salient for residents living in close proximity in rural China, while relatives and classmates are salient reference groups for urban residents. According to Knight et al. (2009), 68 percent of survey respondents in China reported that their main comparison group consisted of individuals in their own village, whereas only 11 percent stated that their main comparison group consisted of individuals from outside of the village.

Existing China studies on RD concentrate on three aspects - saving and consumption, health, and happiness. In the following discussions, I relate their empirical findings to policy discourse and finally talk about RD's implication on poverty alleviation and more general development policies.

Regarding saving and consumption, consensus can be reached when nonpositional consumption and positional consumption are distinguished from one another. Since people care about relative social status associated with large pecuniary and non-pecuniary benefits in China, improving social status often rely on signaling accumulated wealth or education attainment. Given underdeveloped credit market in China, people have to save more for positional consumption and cut non-positional goods consumption. When income inequality increases, the benefit gap between the high-status and low-status groups widens and the entry wealth level for the high-status group increases, 
which in turn strengthens saving incentives to increase positional consumption, typically on housing, and reduces non-positional consumption. Future research is expected to investigate potential macroeconomic impacts of RD status, such as high saving rate, low consumption, and escalating housing price in contemporary China.

Moreover, higher RD raises the importance of social inclusion, which incurs large expenditure among the poor (Ravallion and Chen, 2011). There has been a large literature, e.g. Banerjee and Duflo (2007), documenting high spending on gifts and festivals among the poor that serve as essential social roles, and the consequences of refusing to participate are grave. Evidence from China has shown that the poor could spend more on basic food instead of festivals but failed to do so. The studies on RD and social inclusion sheds some light on the "food puzzle" raised by Deaton as to why the nutritional status of the poor tends to be stagnant amid rapid income growth in developing countries (Chen and Zhang, 2012) ${ }^{8}$.

Most studies on RD status and health point to its negative consequences. These findings indicate the importance of economic policies in affecting longterm individual well-being. This is an important issue, since the implementation of differential regional economic policies in China may stimulate large disparities in income growth and health inequality across regions. The issue is further complicated by findings from older adults in China (Ling, 2009) that being less economically deprived may not guarantee better health and neither do those who are more economically deprived have worse health. More research is needed to examine absolute and relative income effects on health inequalities along major health behavior and outcomes.

Studies on RD and happiness attempt to account for two seemingly contradicting trends: average happiness has remained constant over time despite sharp rises in income but, at the same time, positive correlations are found between individual income and measures of subjective well-being. The two trends are puzzling policymaking in the world. China is no exception, and its studies have confirmed the important role played by RD (Knight et al., 2009; Mangyo and Park. 2011). To understand this well-known Easterlin Paradox (1974), we should know how RD works to reconcile the paradox. RD may

\footnotetext{
${ }^{8}$ The popular explanation relates to the reductions in physical activities and the need for calories, but this alone is unable to explain why child malnutrition rate has barely improved.
} 
arise due to positional goods that give utility when most other people do not have them (Frank, 1999) or aspirations formed by relative comparisons that affect utility (Easterlin, 2001). The former is evaluated relative to others (social comparison), while the latter is evaluated relative to oneself in the past (habituation) as well as to others (social comparison).

The strong evidence of $\mathrm{RD}$ in developing countries would point to important trade-off for current development policies and therefore cast serious doubt on the welfare justifications (Ravallion and Lokshin, 2010). Considering the case when relative income imposes counteracting impact (equal to the positive effect of own income) on well-being, an equal proportionate increase in all incomes would have no impact on average well-being. In this case, emphasis placed on promoting economic growth in poor countries can be questioned. Meanwhile, promoting poverty reduction without considering their income gains on social comparators would entail welfare efficiency costs, as poor people face inefficiently high incentives to escape poverty without taking account of their negative spillover effect.

Finally, the idea of RD can be generalized to analyze social competition in other aspects, though this entry focuses on relative income and relative consumption. For example, owning a house was not a prerequisite to getting married twenty years ago. However, skewed sex ratio favoring girls due to the combination of son preference and implementation of the One Child Policy has totally changed this situation in the last ten years. At present, families with son, especially those without a house, are relatively deprived in the marriage market, which bears long-term impacts that worth further investigation with the help of RD. 


\section{References}

Banerjee, A. and E. Duflo. 2007. The economic lives of the poor. Journal of Economic Perspectives. 21(1): 141-168.

Brown, P., E. Bulte, and X. Zhang. 2011. Positional spending and status seeking in rural China. Journal of Development Economics. 96: 139-149.

Carlsson, F. and P. Qin. 2010. It is better to be the head of a chicken than the tail of a phoenix: Concern for relative standing in rural China. The Journal of Socio-Economics. 39(2): 180-186.

Chen, X. and X. Zhang. 2012. Costly posturing: relative status, ceremonies and early child development in China. World Institute for Development Economic Research (UNU-WIDER) Research Working Paper \# 2012/70.

Chen, X., Kanbur, R. and X. Zhang. 2012. Peer effect, risk-pooling and status seeking: What explains gift spending escalation in rural China? CEPR Working Paper \# 8777.

Cooper, B., C. Garcia-Penalosa. and P. Funk. 2001. Status effects and negative utility growth. Economic Journal. 111: 642-665.

Deaton, A. 2001. Relative deprivation, inequality, and mortality. NBER Working Paper \#8099.

Easterlin, R. 1974. Does economic growth improve the human lot? Some empirical evidence. in Paul A. David and Melvin W. Reder, eds., Nations and Households in Economic Growth: Essays in Honor of Moses Abramovitz, New York: Academic Press, Inc. 89-125.

Easterlin, R. 2001. Income and happiness: towards a unified theory. Economic Journal 111: 465-484.

Frank, R.H., 1999. Luxury Fever: Why Money Fails to Satisfy in an Era of Excess. Free Press, New York.

Gerdtham, Ulf-G. and M. Johannesson. 2004. Absolute income, relative income, income inequality, and mortality. Journal of Human Resources. 39 (1): 228-248.

Jin, Y., B. Wu. and H. Li. 2010. Income inequality, status seeking, and consumption. MPRA Paper, University Library of Munich. http://EconPapers.repec.org/RePEc:pra:mprapa:22641. 
Knight, J., L. Song. and R. Gunatilaka. 2009. Subjective well-being and its determinants in rural China. China Economic Review. 20(4): 635-649.

Li, H. and Y. Zhu. 2006. Income, income inequality, and health: Evidence from China. Journal of Comparative Economics. 34(4): 668-693.

Ling, D. 2009. Do the Chinese 'keep up with the joneses'? Implications of growing economic disparities and relative deprivation on health outcomes among older adults in China. China Economic Review. 20(1): 65-81.

Mangyo, E. and A. Park. 2011. Relative deprivation and health: Which reference groups matter? Journal of Human Resources. 46(3):459-481.

Marmot, M., G. Davey-Smith. et al. 1991. Health inequalities among British civil servants: The Whitehall II study. Lancet. 337 (8754): 1387-1393.

Ravallion, M. and S. Chen. 2011. Weakly relative poverty. Review of Economics and Statistics. 93(4): 1251-1261.

Ravallion, M. and M. Lokshin. 2010. Who cares about relative deprivation? Journal of Economic Behavior \& Organization. 73(2): 171-185.

Runciman, W.G., 1966. Relative Deprivation and Social Justice. Routledge and Kegan Paul, London.

Stark, O. and S. Yitzhaki. 1988. Labor migration as a response to relative deprivation. Journal of Population Economics. 1 (1): 57-70.

Sun, W. and X. Wang. 2012. Do relative income and income inequality affect consumption? Evidence from the villages of rural China. Journal of Development Studies. 1-14.

Wildman, J. 2003a. Modeling health, income and income inequality: The impact of income inequality on health and health inequality. Journal of Health Economics. 22, 521-538.

Wildman, J. 2003b. Income related inequalities in mental health in Great Britain: Analyzing the causes of health inequality over time. Journal of Health Economics. 22, 295-312.

Yitzhaki, S. 1979. Relative deprivation and the Gini coefficient. Quarterly Journal of Economics. 93(2): 321-24. 